\title{
Estimating the contribution of assembly activity to cortical dynamics from spike and population measures Michael Denker*1, Sébastien Roux ${ }^{2}$, Alexa Riehle ${ }^{3}$, Markus Diesmann ${ }^{1,4}$ and Sonja Grün ${ }^{1}$
}

\author{
Address: ${ }^{1}$ Theoretical Neuroscience Group, RIKEN Brain Science Institute, Wako City, Japan, ${ }^{2}$ Bernstein Center for Computational Neuroscience \\ (BCCN), Albert-Ludwigs University, Freiburg, Germany, ${ }^{3}$ Mediterranean Institute of Cognitive Neuroscience (INCM), CNRS - Univ. Aix-Marseille \\ 2, Marseille, France and ${ }^{4}$ Brain and Neural Systems Team, RIKEN Computational Science Research Program, Wako City, Saitama, Japan \\ Email: Michael Denker* - mdenker@brain.riken.jp \\ * Corresponding author
}

from Eighteenth Annual Computational Neuroscience Meeting: CNS*2009

Berlin, Germany. 18-23 July 2009

Published: 13 July 2009

BMC Neuroscience 2009, I0(Suppl I):P23I doi:I0.II86/I47I-2202-I0-SI-P23I

This abstract is available from: http://www.biomedcentral.com/I47I-2202/I0/SI/P23 I

(C) 2009 Denker et al; licensee BioMed Central Ltd.

An inspiring yet hotly debated hypothesis is that cortical networks employ the coordinated activity of groups of neurons, termed assemblies, as a means to code information. Despite recent advances in increasing the number of recorded neurons from cortical networks and new analysis tools to handle the complex data of such experiments, the massive undersampling of the system still deprives us of the possibility to directly observe assembly activity in the living brain. However, a growing body of experimental studies indirectly substantiates the assembly idea with findings of behavior-related significant synchronous spiking activity [1]. Independently thereof, a mesoscopic signal probing the neural population, like the local field potential (LFP), typically exhibits temporally structured oscillations commonly interpreted as correlated network activity. Likewise, the occurrence and strength of such oscillations have been linked to a variety of behavioral aspects. Recently, we demonstrated a direct link between coincident spike events and LFP beta oscillations in motor cortex of the awake-behaving monkey [2]. In particular, we showed that assembly activity detected by the Unitary Event (UE) analysis [3] as a significant surplus of spike synchrony exhibits an exceptionally strong phase locking to the LFP that cannot be explained by the locking of the individual neurons.
To understand how the observed levels of synchrony and phase locking quantitatively relate to the assembly hypothesis, we formulate a simplified model based on our experimental results. It assumes that part of the spiking activity is involved in assembly activations, whereas the other part is not. In the model, UEs explicitly express observed assembly activity. Combined with the results in [2], we conclude that assembly spikes are more strongly entrained by the LFP than non-assembly spikes. In this framework, we compute the minimal relative contribution of assembly spikes in UE periods following two conceptually different approaches. First, we show how to estimate the fraction of spikes involved in assembly activations by comparing the phase distributions between time periods that exhibit UEs and those that do not. Second, we estimate this fraction analytically as a function of the UE significance level independent of the LFP. In this approach we use a model of injected spike synchrony into otherwise independent firing [4], and exploit estimates of the expected and empirical coincidence distributions. Both methods are calibrated using simulated data before they are applied to the cortical data. A comparison finds the fractional contribution of assemblies to the neuronal dynamics estimated by the two independent methods in good agreement. Finally, an extension of the former approach enables us to infer an estimate of the percentage of spikes a neuron contributes to assemblies. The consist- 
ency of the results of both approaches provides encouraging support for the assembly hypothesis and furthermore suggests that a parallel coding scheme of rate and synchrony is a likely explanation of the experimental findings.

\section{Acknowledgements}

Partially funded by the Helmholtz Alliance on Systems Biology, the French National Research Agency (ANR-05-NEUR-045-0I), and EU grant 15879

(FACETS).

\section{References}

I. Riehle A, Grün S, Diesmann M, Aertsen A: Spike synchronization and rate modulation differentially involved in motor cortical function. Science 1997, 278:1950-1953.

2. Denker M, Roux S, Lindén H, Diesmann M, Riehle A, Grün S: Reflections of synchronous spiking activity in local field potentials. Soc Neurosci Online Abstract Viewer/ltinerary Planner 2007. Program No. 793.4.

3. Grün S, Diesmann M, Aertsen A: Unitary events in multiple single-neuron spiking activity: II. Nonstationary data. Neural Comp 2002, 14:8I-I 19.

4. Grün S, Diesmann M, Grammont F, Riehle A, Aertsen A: Detecting unitary events without discretization of time. J Neurosci Meth 1999, 94:67-79.
Publish with Bio Med Central and every scientist can read your work free of charge

"BioMed Central will be the most significant development for disseminating the results of biomedical research in our lifetime. "

Sir Paul Nurse, Cancer Research UK

Your research papers will be:

- available free of charge to the entire biomedical community

- peer reviewed and published immediately upon acceptance

- cited in PubMed and archived on PubMed Central

- yours - you keep the copyright

Submit your manuscript here:

http://www.biomedcentral.com/info/publishing_adv.asp 